\title{
Influências na constituição do currículo oficial na Rede Municipal de Ensino de São Paulo
}

Raíssa de Oliveira Chappaz*

Bárbara Barbosa Born**

*Mestranda em Educação pela Faculdade de Educação da Universidade de São Paulo (Feusp) e professora de educação infantil na Rede Municipal de Ensino de São Paulo

E-mail: issachappaz@yahoo. com.br

**Mestranda em Educação pela Faculdade de Educação da Universidade de São Paulo (Feusp) e professora de história no ensino fundamental II na Rede Municipal de Ensino de São Paulo

E-mail: barbarabornprof@ gmail.com
Resumo: As políticas curriculares ocupam lugar central no debate educacional. Em consequência da adoção dessas como propulsoras de mudanças pelos governos federal, estaduais e municipais, tal temática vem ganhando força na produção acadêmica brasileira. As mudanças educacionais e outros aspectos envolvidos em tais processos nas últimas décadas também têm produzido particular efeito sobre o currículo. 0 presente artigo problematiza quais seriam as possíveis influências em sua constituição ao investigar a política curricular do ensino fundamental na Rede Municipal de Ensino de São Paulo. Tal investigação concentra-se nas formulações de políticas entre os anos 2005 e 2012, buscando evidenciar influências tais como as avaliações externas, questões políticopartidárias e comerciais.

Palavras-chave: Currículo oficial. Avaliação externa e currículo. Rede Municipal de Ensino de São Paulo. 
No amplo espectro do debate educacional, certamente a temática curricular ocupa lugar central. 0 tema currículo, por si, já congrega uma multiplicidade de debates. Dentre eles, faz-se importante destacar o papel das ações do Estado no que tangem à definição curricular, visto que é possível observar no Brasil, a partir da década de 1990, uma intensificação de iniciativas no sentido de definir parâmetros e expectativas de aprendizagem, encetados tanto pelos órgãos federais quanto por secretarias estaduais e municipais de educação.

Desse modo, a ação do Estado no que diz respeito à educação se expressa por meio das políticas públicas que são ações emanadas de governos, trazendo consigo forte carga de interesses, necessidades, concepções e ideais político-partidários. Para Figueiredo e Figueiredo (1986, p. 109), essas políticas possuem dois aspectos: de um lado, a geração de um produto que é "físico, tangível e mensurável”, e de outro a geração de um impacto que "tanto pode ser físico, tangível e mensurável, quanto subjetivo, alterando atitudes, comportamentos e/ou opiniões". Esses autores afirmam, ainda, que é esperado pelos governos, necessariamente, algum impacto quando as políticas são decididas.

Nesse sentido, as políticas curriculares podem ser entendidas como ações emanadas pelo Estado (governos municipais, estaduais e federal, representados por suas secretarias de educação) que buscam definir um currículo oficial que se constitui de diretrizes, orientações, conteúdos, aprendizagens, ensino, organização dos tempos escolares, etc. Esse currículo concentra assim um alto poder de mudança, que vai além das alterações curriculares em si, e contribui na legitimação de processos. Segundo Lopes,

As práticas curriculares anteriores à reforma são negadas e/ou criticadas como desatualizadas, de forma a instituir o discurso favorável ao que será implantado: mudanças nas políticas educacionais visando à constituição de distintas identidades pedagógicas

(LOPES, 2002c) consideradas necessárias ao projeto político-social escolhido.

Se por um lado o currículo assume o foco central da reforma, por outro as escolas são limitadas à sua capacidade, ou não, de implementar adequadamente as orientações curriculares oficiais.

o currículo oficial, com isso, assume um enfoque, sobretudo, prescritivo. Por vezes o meio educacional se mostra refém dessa armadilha e se envolve no seguinte debate: os dirigentes questionam as escolas por não seguirem devidamente as políticas oficiais, e os educadores criticam o governo por produzir políticas que as escolas não conseguem implantar. Em ambos os casos, parece-me, tem-se o entendimento da prática como o espaço de implantação das propostas oficiais, sendo as políticas curriculares interpretadas como produções do poder central - no caso, o governo federal (LOPES, 2004, p. 110). 
Assim, considerando que as políticas curriculares possuem potencial para influenciar os processos pedagógicos e a centralidade que elas têm assumido nas políticas educacionais, havendo uma sobreposição das políticas curriculares a outros elementos da reforma educacional, faz-se importante também considerar que há diversos fatores imbricados na constituição de uma proposta curricular.

Por conseguinte, para entender o currículo oficial desenvolvido é necessário apreender as influências que envolvem a sua constituição. A Rede Municipal de Ensino de São Paulo (RME-SP) é um locus privilegiado para se proceder a essa análise. Sendo a maior rede municipal de ensino do país, com quase 1 milhão de alunos, 1.459 escolas de administração direta (das quais 546 são de ensino fundamental) e 83,8 mil funcionários, ela possui uma vasta produção curricular própria, tendo suas políticas utilizadas como modelo para as demais redes.

Embora essa Rede tenha passado por inúmeras reorganizações curriculares desde finais da década de 1980, percebe-se como momento privilegiado de análise de tais mudanças o intervalo entre 2005 e 2012, pois há farta documentação a respeito das transformações, inseridas em um contexto de reforma educacional. Por meio dessa documentação buscou-se apreender quais seriam os fatores de influência na composição do currículo oficial na RME-SP.

\section{CURRÍCULO: APORTES TEÓRICOS PARA FORMULAÇÃO DE UMA PERSPECTIVA}

Cada teoria de currículo tem sua origem em um contexto político, social e econômico que influencia a forma como lida com a seleção do que deve ser ensinado. De acordo com Silva,

O currículo é sempre resultado de uma seleção: de um universo mais amplo de conhecimentos e saberes seleciona-se aquela parte que vai constituir, precisamente, o currículo. As teorias do currículo, tendo decidido quais conhecimentos devem ser selecionados, buscam justificar por que "esses conhecimentos" e não "aqueles" devem ser selecionados. [...] outra importante pergunta: "o que eles ou elas devem ser?” ou, melhor, "o que eles ou elas devem se tornar?”. Afinal, um currículo busca precisamente modificar as pessoas que vão "seguir" aquele currículo. Na verdade, de alguma forma, essa pergunta precede à pergunta "o que?", na medida em que as teorias do currículo deduzem o tipo de conhecimento considerado importante justamente a partir de descrições sobre o tipo de pessoas que elas consideram ideal (SILVA, 2011, p. 15). 
Dessa maneira, ao selecionar, privilegiar, destacar e descartar, o currículo se constitui como um instrumento com potencial de influenciar a estrutura da escolarização e práticas pedagógicas. Essa atuação se evidencia, inicialmente, no processo de expansão da escolarização, quando o conceito de currículo passa a ter uma forte presença no discurso educacional, pois “a própria lógica da 'educação para todos' exige que, em prol da igualdade, os conteúdos sejam dosados e organizados dentro de um sistema escolar desenvolvido" (SACRISTÁN, 2013, p. 20). É preciso considerar, assim, que o currículo possui um espectro de dimensões que vão desde a retórica das declarações, dos propósitos e das ideias até a prática, assumindo a perspectiva do currículo como um processo amplo e complexo.

Como consequência da existência de uma multiplicidade de mediações entre a produção científica do conhecimento e o currículo, por meio de seus diferentes interlocutores, é possível observar a existência de diferentes definições. Dentre elas, a apresentada por Lopes e Macedo é significativa na medida em que abrange a complexidade do campo:

[...] consideramos que o campo do Currículo se constitui como um campo intelectual: espaço em que diferentes atores sociais, detentores de determinados capitais social e cultural na área, legitimam determinadas concepções sobre a teoria de Currículo e disputam entre si o poder de definir quem tem a autoridade na área. Trata-se de um campo capaz de influenciar propostas curriculares oficiais, práticas pedagógicas nas escolas, a partir dos diferentes processos de recontextualização de seus discursos, mas que não se constitui dessas mesmas propostas e práticas. O campo intelectual do Currículo é um campo produtor de teorias sobre currículos, legitimadas como tais pelas lutas concorrenciais nesse mesmo campo. As produções do campo do Currículo configuram, assim, um capital objetivado do campo

(LOPES; MACEDO, 2010, p.17-18).

No Brasil, as reflexões teóricas acerca do currículo tomaram corpo nos anos 1920, mas até a década de 1980 elas foram primordialmente pautadas pela experiência estadunidense - que trazia um referencial funcionalista -, o que resultou, no que diz respeito às políticas curriculares, em processos de assimilação de modelos.

A partir dos anos de 1980 novas correntes ganham espaço e teorizam sobre questões pertencentes ao campo do currículo. Entre as principais influências internacionais no pensamento curricular brasileiro estava a Nova Sociologia da Educação (NSE) inglesa, de Michel Apple e Henry Giroux. Conforme Souza (1993) destaca, houve um esforço de reinterpretação dos autores e de incorporação de elementos ligados ao contexto local do campo da educação. Nesse período, algumas importantes tendências interpretativas do currículo ganham destaque, como a pedagogia libertadora (educação popular), proposta por Paulo Freire, e a pedagogia histórico-crítica, proposta 
por Saviani (SILVA, 2011).

Simultaneamente, iniciou-se no país um movimento de reorientação curricular encabeçado por estados das regiões Sudeste e Sul (MOREIRA, 2012), que, em meio à transição democrática, expressavam um discurso marcado pela necessidade de participação democrática e de recuperação da relevância social dos conteúdos, como é possível apreender em Barretto:

\begin{abstract}
Afirmava-se o caráter social do processo de produção do conhecimento, para o qual toda a sociedade contribui, sendo que dele poucos se apropriam. De acordo com a pedagogia crítico-social dos conteúdos - dominante nas orientações oficiais -, a escola deveria buscar soluções pedagógicas adequadas às características e necessidades dos alunos das camadas populares, visando a assegurar a todos verdadeiras condições de reivindicarem seus direitos e a dar-lhes instrumentos para lutarem por uma sociedade mais justa mediante o domínio efetivo dos conhecimentos. A escola para os conteudistas, como eram chamados, era considerada um local privilegiado de transmissão do saber valorizado socialmente aos segmentos majoritários da população, ao qual estes não teriam acesso de outra maneira (BARRETTO, 2006, p. 4).
\end{abstract}

Desse modo, entre a década de 1980 e o início da década de 1990, o debate sobre currículo assumiu um caráter sociológico, compreendido como espaço de relações de poder. "As proposições curriculares cediam espaço a uma literatura mais compreensiva do currículo, de cunho eminentemente político" (LOPES; MACEDO, 2010, p. 14). De acordo com Barretto (1998), o destaque dado à democratização e à participação social passou a ir além do discurso, estando presente também nos diferentes componentes curriculares por meio de uma nova concepção da função da escola (educação para a cidadania). Tal preocupação se evidenciou por meio da disseminação de mecanismos de gestão democrática na escola, de medidas para a melhoria do fluxo e do olhar sobre as necessidades dos alunos, de modo que se ampliaram os direitos à educação, fato que também foi influenciado pelo estabelecimento da nova Constituinte.

Assim, durante a primeira metade da década de 1990, havia certa hegemonia no discurso de que o currículo só seria compreendido se contextualizado política, econômica e socialmente. A intensidade das mudanças sociais que marcou essa década teve papel importante, pois ao trazer novas interpretações das relações produtivas, somadas ao contexto de Reforma do Estado - a qual estimulou reflexões acerca do papel do Estado com relação às políticas sociais e conferiu uma nova lógica de gestão pública - fizeram surgir novos enfoques na questão curricular, com a adoção dos referenciais pós-modernos e pós-estruturais.

O diálogo produzido com as diversas vertentes resultou naquilo que Lopes e Macedo (2010) denominam “híbridos culturais". Essa pluralidade de 
perspectivas teóricas levou para os discursos curriculares um elemento fundamental para a constituição do currículo, destacado por Dussel ao falar das contribuições de Kliebard: a noção de ajustes aos diferentes interesses presentes na sociedade. Ou seja, a consideração de que na educação há rearticulação de discursos que são diversificados e que produzem efeitos profundos na estrutura do sistema educativo, na medida em que instituem novas lógicas e as legitimam por meio do currículo.

O currículo flutua constantemente ao longo do tempo em resposta às necessidades sociais e econômicas. Além disso, em um dado momento, ele não é uma reflexão coerente e explícita sobre o que uma sociedade espera que suas crianças e adolescentes saibam. Até as expressões formais e documentadas sobre aquilo que os currículos devem ser não são nada consistentes, sendo frequentemente contraditórias. [...] Nesse sentido, o currículo representa mais um cruzamento nebuloso de interesses de variados grupos em uma sociedade do que uma expressão articulada de forma unificada e não ambígua de valores de uma cultura

\section{CURRÍCULO OFICIAL NA RME-SP}

Um momento significativo das políticas curriculares na RME-SP ocorreu entre os anos de 2005 e 2012 quando José Serra assumiu a prefeitura de São Paulo, sendo substituído pelo vice-prefeito, Gilberto Kassab, no ano de 2006, reeleito em 2008. Durante essa administração a Rede passou por uma reforma educacional que teve como frentes a reorganização curricular e a instituição de uma avaliação externa própria. Trata-se de um período fértil para se buscarem evidências das possíveis influências na configuração do currículo oficial.

Tal reforma foi promovida com base na constatação, por parte dos gestores da Rede, de uma defasagem no desenvolvimento das competências leitora e escritora entre os educandos, a partir de um estudo encomendado ao Ibope/ Ação Educativa no ano de 2005, que constatou que o número de alunos de 3ำ ano que não escreviam convencionalmente na Rede era elevadíssimo, chegando a $30 \%$ em algumas escolas, além do fato de que a taxa de reprovação ao final do ciclo I do ensino fundamental (então $4^{\circ}$ ano) era da ordem de $12 \%$.

Diante desse quadro, um dos alicerces da política da SME-SP durante essa gestão foi o "Programa Ler e Escrever - prioridade na Escola Municipal”, que objetivou desenvolver as competências leitora e escritora dos alunos. Para tanto foram elaborados materiais formativos para os professores e didáticos para os alunos, evidenciando ações cujo objetivo era, de fato, alcançar o trabalho em sala de aula. 
No que tange à reorganização curricular, podem ser definidas três frentes de ação:

- O Programa Ler e Escrever, composto de materiais voltados para professores, projetos de reforço das competências leitora e escritora no $1^{0}$ ano e de recuperação de alunos retidos no $4^{\circ}$ ano.

- A elaboração de Orientações Curriculares para todas as disciplinas.

- A elaboração dos Cadernos de Apoio e Aprendizagem, que se constituíam como material didático distribuído para todos os estudantes do ensino fundamental nas áreas de Língua Portuguesa e Matemática, inicialmente, e de Natureza e Sociedade a partir do ano de 2012.

\section{O Programa Ler e Escrever}

O Programa Ler e Escrever foi planejado em três etapas: a primeira era chamada de “Toda Força ao 1ํa ano - TOF”, propondo a presença de um estudante universitário de Letras ou Pedagogia acompanhando e auxiliando o trabalho do professor na sala de aula do $1^{\underline{0}}$ ano do ensino fundamental; a segunda era o "Projeto Intensivo no Ciclo I - PIC", que se resume à formação de uma sala de aula com até 35 alunos que foram retidos no $4^{\circ}$ ano, tendo se ampliado em 2008 para alunos que chegam ao 30 ano do ensino fundamental sem 0 domínio do sistema alfabético de escrita; e, por fim, o "Projeto Ler e Escrever em Todas as Áreas no Ciclo II" propunha que professores das diferentes áreas do conhecimento trabalhassem a leitura e a escrita.

Esse programa foi instituído pela Portaria SME no 6.328, de 26 de setembro de 2005, tendo como objetivo declarado a necessidade de superar o fracasso escolar provocado pelo analfabetismo, por meio de programas específicos que visavam reverter esse quadro. Em 2007, o Programa Ler e Escrever passou por uma reorganização, sendo composto dos seguintes eixos: "Toda Força no 1ํano do Ciclo I - TOF”; “Projeto Intensivo no Ciclo I - PIC” para 3ํㅡ e 4ํanos; “Projeto Ler e Escrever nos 2ํㅗ, 3ํs e 4ํs anos do Ciclo I"; "Ler e Escrever em Todas as Áreas do Conhecimento do Ciclo II”; e o projeto "Compreensão e Produção de Linguagem Escrita por Alunos Surdos".

O desenvolvimento das competências leitora e escritora permanecia como base daquilo que o Programa considerava sucesso nas aprendizagens, justificando a elaboração de um projeto com foco no $1^{0}$ ano, chamado TOF. 
Por meio da formação dos coordenadores pedagógicos e dos professores alfabetizadores, a SME-SP objetivava assegurar que os educandos do $1^{\underline{0}}$ ano conseguissem ler e escrever com certa autonomia ao final desse período de escolarização.

Foram editados três volumes com o título Guia de Planejamento para o Professor Alfabetizador - Orientações para o planejamento e avaliação do trabalho com o $1^{\circ}$ ano do Ensino Fundamental - Ciclo I (SÃO PAULO, 2006a, 2006b, 2006c). Eles se constituíram, naquele momento, como um currículo a ser trabalhado dentro das salas de aula de alfabetização. Contemplavam desde aspectos conceituais, passando pela definição de expectativas e metas de aprendizagem, até formas de avaliar os educandos. Também estavam presentes nesses volumes modelos de atividades que poderiam ser trabalhadas com os estudantes do $1^{\circ}$ ano.

Ao analisar o Guia, percebe-se que se trata de material profundamente prescritivo. Sua estrutura gráfica e principalmente a construção textual fazem com que ele se assemelhe a um material didático voltado aos professores, cujo objetivo era apresentar o "passo a passo" do trabalho em sala de aula: estabelecem expectativas bimestrais de aprendizagem; sugestões de atividades para cada uma das expectativas; maneiras de efetuar a avaliação das aprendizagens, realizada através das sondagens; disponibilização de um quadro de planejamento semanal e até mesmo uma descrição da melhor maneira de organizar a rotina em sala de aula.

É interessante notar que a SME/DOT (Diretoria de Orientação Técnica) apresenta o Guia como um suporte, não como material prescritivo do trabalho em sala de aula, o que entra em contradição, contudo, com a forma como ele se estrutura e com a própria postura impositiva da adoção do Programa em todas as escolas (SÃO PAULO, 2006a).

O segundo eixo do Programa Ler e Escrever foi o Projeto Intensivo no Ciclo $I$ - PIC, destinado às turmas de 30 e $4^{\circ}$ anos do ciclo I. Esse projeto previa a criação de turmas diferenciadas nos respectivos anos com o objetivo de promover, de acordo com a Portaria no 5.403/07 (SÃO PAULO, 2007a), uma recuperação intensiva dos conteúdos curriculares dos alunos que chegaram a essas etapas sem suficiente avanço em alfabetização.

As turmas de $3^{\circ}$ ano PIC seriam montadas observando o seguinte critério: até 30 alunos que tivessem finalizado o $2^{\circ}$ ano do ciclo I sem demonstrarem a construção de conhecimentos suficientes sobre o sistema alfabético de 
escrita, de acordo com as sondagens de alfabetização propostas. Já as turmas de $4^{0}$ ano deveriam ser montadas com alunos que, ao final desse período, ficassem retidos no ciclo $\mathrm{I}$.

Para as turmas de PIC foram produzidos materiais de uso dos professores e dos educandos. $03^{\circ}$ ano PIC possuía um volume que congregava as atividades de Língua Portuguesa e Matemática para os alunos, e para o professor, além das atividades constantes no livro do aluno, havia os pressupostos teóricos e metodológicos do projeto. O material era composto de proposta de trabalho para todo o ano letivo, com ênfase em atividades voltadas ao domínio do sistema alfabético de escrita (SÃO PAULO, 2011a).

Já o material do 4ํano PIC era dividido em dois volumes para o professor e dois para os alunos, sendo um de Língua Portuguesa e outro de Matemática. Ele era apresentado ao professor como sua "ferramenta de trabalho" (SÃO PAULO, 2011b, p. 3). Sua estrutura era um pouco diferente do material do $3^{\circ}$ ano, pois ele se orienta com base nas atividades constantes no livro do aluno, explicando como o professor devia proceder em cada uma das atividades propostas. Tanto no texto de apresentação, elaborado pelo secretário de Educação Alexandre Alves Schneider, quanto no elaborado pela equipe de DOT/SME exaltava-se que o professor possuía autonomia na organização de seu trabalho. Essa autonomia, contudo, estaria restrita à escolha de qual atividade do material trabalhar primeiro, e não na verdadeiramente autônoma escolha de atividades pelo educador.

0 terceiro eixo do Programa Ler e Escrever era o Projeto Ler e Escrever nos $2^{\circ}-$, $3^{\circ}$ S e $4^{\circ}$ S anos do Ciclo I (SÃO PAULO, 2007a). Ele partia da compreensão de que, embora o investimento no $1^{0}$ ano do ciclo I seja fundamental, ele não era suficiente, sendo necessárias outras ações ao longo deste ciclo para que os educandos "cheguem ao final do Ciclo I sabendo utilizar a linguagem oral e escrita nas diversas situações comunicativas, ampliando suas possibilidades de participação social no exercício da cidadania”.

Foram publicados quatro volumes destinados ao planejamento dos professores: em 2007, o material voltado para o $2^{\circ}$ ano, que era dividido em dois volumes (SÃO PAULO, 2007b; 2007c) e em 2008, um volume para o 3ํano e um volume para o 4ํano (SÃO PAULO, 2008a, 2008b). De acordo com o texto introdutório desse material, ele foi criado com o intuito de dar continuidade ao trabalho que fora desenvolvido desde 2006 com as turmas de $1^{\stackrel{0}{ }} \mathrm{~s}$ anos. 
Os volumes do $2^{\circ}$ ao $4^{\circ}$ ano contemplavam, além do trabalho em Língua Portuguesa, atividades em Matemática. Em todos havia a proposição de diferentes modalidades organizativas do trabalho docente: atividades permanentes, sequências didáticas e projetos didáticos. Dentro de cada um, diversas atividades davam a tônica do trabalho a ser desenvolvido pelos professores em sala de aula.

A novidade desse material foi o diálogo, nos volumes destinados aos $3^{\circ}$ e $4^{0}$ anos, com as Orientações Curriculares que foram publicadas no mesmo ano, de 2008. Eles passaram a se referir diretamente ao documento, afirmando que as propostas de trabalho desenvolvidas no material foram baseadas nas proposições de expectativas de aprendizagem para os respectivos anos.

Sobre o potencial que esse material possuía para influenciar o trabalho desenvolvido pelos professores em sala de aula, foram significativas as palavras do então secretário de Educação, Alexandre Alves Schneider, acerca dos objetivos desse programa:

[...] a publicação dos materiais do Ler e Escrever representa a concretização de uma política pública direcionada à melhoria do ensino enquanto instrumento de acompanhamento para os gestores, canal de comunicação entre os coordenadores e professores e, por fim, efetivo apoio didático em sala de aula.

Assim, com esse volume, desenvolvido especificamente para a rede pública municipal de São Paulo, a exemplo do primeiro, seguimos garantindo aos alunos um leque de atividades didáticas planejadas para consolidar seus conhecimentos sobre leitura e escrita (grifos nossos) (SÃO PAULO, 2007b, p. 5).

Considerar o material como instrumento de acompanhamento para os gestores implicava, na fala do secretário, que o mesmo estivesse sendo utilizado para que o controle pudesse de fato ocorrer. Além disso, ao afirmar que o volume assegurava que os alunos tinham acesso a determinadas atividades planejadas com o intuito de consolidar seus conhecimentos sobre leitura e escrita, ele pressupunha que não apresentar tais atividades seria privar os educandos dessa garantia.

Há outras questões em todos os materiais do Ler e Escrever voltados ao ciclo I que merecem destaque, no que tange ao potencial de influência que elas teriam no trabalho em sala de aula. Embora a adesão ao programa fosse voluntária, as escolas só poderiam negá-la se apresentassem um projeto de trabalho com foco na leitura e escrita que fosse aprovado pela Diretoria Regional de Educação e pela Supervisão Escolar. Além disso, os envolvidos (coordenadores e professores regentes) obrigatoriamente participavam de 
formações com foco no desenvolvimento das etapas do programa, sendo a disponibilidade para formação um critério de atribuição de turmas. Um terceiro elemento crucial para a adesão era o fato de que os professores do TOF e do PIC recebiam pontuação diferenciada para fins de evolução funcional se participassem das formações e assegurassem que os alunos chegariam alfabetizados ao final do período, de acordo com critérios estabelecidos pela SME-SP.

Todos esses materiais também buscavam influenciar a rotina de sala de aula, propondo tabelas detalhadas sobre quais conteúdos deveriam ser abordados em cada dia da semana, influindo inclusive na frequência. Revestidas de uma tônica sugestiva, as ações propostas apresentavam um forte potencial para serem efetivadas, uma vez que os coordenadores pedagógicos - envolvidos em formações do Programa Ler e Escrever e tendo que submeter os resultados de alfabetização da escola à análise de suas Diretorias Regionais de Educação - tenderiam a envolver todo o grupo nas ações do programa.

O quarto eixo do programa era o Projeto Ler e Escrever em Todas as Áreas do Conhecimento do Ciclo II. Ele foi desenvolvido levando em consideração a necessidade de aprofundar o desenvolvimento das competências leitora e escritora nessa segunda etapa da escolarização, sendo fundamental que os alunos aprendessem práticas de leitura e escrita atreladas aos gêneros da esfera escolar e às práticas sociais de leitura e escrita. De acordo com a Portaria no $5.403 / 07$,

Ensinar a ler e a escrever, portanto, não são tarefas exclusivas do professor de Língua Portuguesa. É necessário que os professores das diferentes áreas do conhecimento reflitam sobre quais são os textos próprios de suas áreas e as práticas de leitura e escrita relacionadas a eles e tomem para si a tarefa de ensiná-los (SÃO PAULO, 2007a).

Nesse sentido, foram produzidos dez volumes de Orientações Didáticas: o Referencial de Expectativas para o Desenvolvimento da Competência Leitora e Escritora no Ciclo II do Ensino Fundamental (SÃO PAULO, 2006d) era o caderno principal, destinado aos professores de todas as áreas do conhecimento. Ele trabalhava as características gerais do Programa, os princípios de implementação das atividades de leitura e escrita em todas as áreas do conhecimento, e princípios organizacionais para que cada escola pudesse se preparar de modo a estimular tais competências. Os demais nove volumes se referiam a cada uma das áreas do conhecimento trabalhadas no ciclo II: Língua Portuguesa, Matemática, História, Geografia, Artes, Ciências Naturais, Língua Inglesa, Educação Física e Tecnologias na Educação. Para os fins da 
presente pesquisa, foram analisados o Referencial de Expectativas (SÃO PAULO, 2006d), destinado a todos os professores, e o Caderno de Orientações Didáticas de Língua Portuguesa (SÃO PAULO, 2006e).

Em seu texto inicial, o Referencial era apresentado como uma "ferramenta de trabalho" para o professor de ciclo II, pressupondo a existência de um "contrato" das diferentes instâncias da Rede para assegurar a aprendizagem de todos os alunos. Uma análise global do Referencial e do Caderno permite afirmar que estes eram instrumentos de apoio e não de prescrição, tal como foi observado com o material destinado ao ciclo I. Assim, ao longo de ambos os textos são expostas concepções de leitura, propostas de trabalho com gêneros mais abertas, passíveis de ser incorporadas na rotina de trabalho do professor sem um direcionamento tão rígido.

Nesse sentido, o Referencial se constituiu como um material de auxílio para que o professor do ciclo II organizasse a estrutura das atividades de leitura e escrita. Apresentava ações que necessitavam ser desenvolvidas para que os estudantes pudessem treinar habilidades necessárias para antes, durante e depois da leitura. Essas habilidades, de acordo com o material, só poderiam ser desenvolvidas se fossem realizadas atividades mediadas pelo professor, de modo que eram propostos tópicos "como desenvolver essas habilidades com a turma" para cada uma das expectativas apresentadas. Também havia uma sugestão de avaliação de cada uma das etapas da leitura.

Para que as atividades pudessem ser bem implementadas, o Referencial sugeria um roteiro de investigação do perfil da comunidade e um diagnóstico daquilo que os alunos já sabiam e daquilo que eles ainda necessitam aprender. É importante destacar que um dos instrumentos propostos para a realização do diagnóstico era o estudo dos resultados das avaliações externas realizadas naquele momento: Saeb, Saresp, Enem e Pisa. O documento propunha, inclusive, que as avaliações diagnósticas da escola fossem elaboradas com base no que diziam as avaliações externas. Apresentava ainda, em caráter de sugestão, um modelo de “matriz” para a avaliação diagnóstica.

No Caderno de Orientações Didáticas, a proposta de trabalho contemplava um diálogo com o livro didático utilizado e valorizava a seleção dos trabalhos de acordo com o planejamento do professor. Propunha, ainda, a organização de uma rotina de leitura e a criação de um registro dessas atividades para que o professor procurasse equilibrar, ao longo do tempo, atividades que permitiam o desenvolvimento das habilidades de leitura propostas no Referencial. 
O quinto e último eixo do Programa Ler e Escrever era o Projeto Compreensão e Produção da Linguagem Escrita por Alunos Surdos. Seguindo a mesma lógica do Programa, esse projeto visava contemplar as especificidades da aprendizagem da Língua Portuguesa por alunos surdos, visto ser esta a segunda língua desses estudantes, sendo a primeira a Língua Brasileira de Sinais (Libras). Assim, com base no material produzido para os alunos das escolas regulares, foram produzidos materiais para professores e alunos das escolas com atendimento a estudantes com surdez.

\section{Orientações Curriculares}

No ano de 2007, foi instituído por meio da Portaria no 4.507 (SÃO PAULO, 2007d) o "Programa de Orientações Curriculares: Expectativas de Aprendizagens e Orientações Didáticas”. Ele foi criado levando em consideração, entre outros aspectos, a necessidade do estabelecimento de metas de aprendizagens para os alunos, a instituição do Sistema de Avaliação de Aproveitamento Escolar dos Alunos da Rede Municipal de Ensino de São Paulo e o já existente Programa Ler e Escrever.

Foram publicadas Orientações Curriculares para todas as áreas do conhecimento que constavam no currículo da RME-SP de ciclo II, além de cadernos específicos para Educação de Jovens e Adultos (EJA), Libras, Língua Portuguesa para pessoas surdas, Expectativas para a Educação ÉtnicoRacial e um caderno para o ciclo I. Para efeitos de análise serão utilizadas as Orientações Curriculares para Ciclo I (SÃO PAULO, 2007e) e as Orientações Curriculares de Língua Portuguesa para Ciclo II (SÃO PAULO, 2007f). Esses documentos foram elaborados ao longo do ano de 2007 e implementados a partir de 2008 em todas as escolas da Rede. 0 objetivo declarado era o de

\footnotetext{
[...] contribuir para a reflexão e discussão sobre o que os estudantes precisam aprender, relativamente a cada área do conhecimento, construindo um projeto curricular que atenda às finalidades da formação para a cidadania, subsidiando as escolas na seleção e organização de conteúdos mais relevantes a serem trabalhados nos nove anos do Ensino Fundamental, que precisam ser garantidos a todos os estudantes (SÃO PAULO, 2007e, p. 12).
}

Em todos os volumes das Orientações Curriculares havia duas partes comuns: a primeira, que apresentava o programa e o articulava com as outras ações da RME-SP; e a segunda, que apresentava seus fundamentos legais, conceitos de aprendizagem e avaliação, os critérios utilizados para seleção das expectativas e quais aspectos a escola devia considerar para implementar o programa na unidade. 
Com relação aos demais programas que já vigoravam na Rede, o documento dá destaque ao Ler e Escrever e à recém-implementada Prova São Paulo. Afirmava a necessidade de articulação entre as diferentes ações da SME-SP para que se efetivasse um ensino de qualidade. Tratava-se, de acordo com o documento (SÃO PAULO, 2007e, p. 16), de diferentes estratégias cujo intuito era "oferecer possibilidades de enriquecimento do currículo e subsidiar o desenvolvimento do projeto pedagógico das escolas da Rede Municipal de Ensino".

Os critérios declarados para a seleção das expectativas de aprendizagem eram: relevância social e cultural; relevância para formação intelectual do aluno e potencialidade para a construção de habilidades comuns; potencialidade de estabelecimento de conexões interdisciplinares e contextualizações; acessibilidade e adequação aos interesses da faixa etária.

Para o ciclo I, as expectativas de aprendizagem estavam organizadas em torno de três grandes campos de conhecimento: Língua Portuguesa e Matemática; Natureza e Sociedade; Arte e Educação Física (SÃO PAULO, 2007e). Nas Orientações Curriculares de Língua Portuguesa para o Ciclo II, partia-se do princípio de que a finalidade desse componente curricular era possibilitar aos educandos o uso adequado da língua, fosse na modalidade escrita ou oral, permitindo que ele participasse das práticas sociais de leitura e escrita.

Como forma de assegurar que as orientações chegassem às escolas, a SMESP promoveu com certa frequência formações acerca de suas expectativas, procurando atender um grande número de professores da Rede. Do mesmo modo, as orientações estavam disponíveis para amplo acesso por meio de seu site e eram pré-requisitos para ingresso dos novos professores na Rede na medida em que eram exigidas nos concursos públicos realizados.

\section{Cadernos de Apoio e Aprendizagem}

Em 2009 a SME-SP produziu, em parceria com a Fundação Padre Anchieta, os Cadernos de Apoio e Aprendizagem. Trata-se de um material de caráter didático complementar aos livros didáticos, para alunos e professores, do 1ํa a 9ano, em Língua Portuguesa e Matemática. Na apresentação desses Cadernos de Apoio (SÃO PAULO, 2010, p. 9), a sua produção era justificada por "contemplar as especificidades da rede pública municipal paulistana do ponto de vista de suas realidades regionais, das condições de acervo de livros, de equipamentos disponíveis, de espaços físicos das escolas e do processo de formação de educadores [...]”. 
Dentro de cada uma das esferas de circulação proposta eram trabalhados gêneros textuais que variavam de ano para ano, evidenciando uma organização espiralar que visa à construção das competências, na medida em que trabalhavam as metas de desenvolvimento em graus de complexidade crescente.

Os Cadernos de Apoio estavam organizados a partir da compreensão de que o domínio da língua permitia o desenvolvimento de habilidades necessárias para a participação nas práticas sociais. A aprendizagem da língua, por sua vez, se organizava em torno do texto, objeto de estudo e, igualmente, foco principal da proposta de avaliação. No que diz respeito à relação das questões propostas com as expectativas de aprendizagem, o texto de apresentação dos Cadernos de Apoio afirma que

\footnotetext{
Nos Cadernos do professor, as atividades estão acompanhadas das respectivas expectativas de aprendizagem para o ano, o gênero e a prática de linguagem contemplada, com a mesma formulação presente no documento de orientações curriculares. Essas são as aprendizagens que se espera que todos os alunos construam [...] Algumas atividades abrangem expectativas propostas para anos ou ciclos posteriores, o que se justifica por se tratar de um processo de construção em que é importante que o que se espera ver consolidado em determinado ano seja processualmente trabalhado desde os anos anteriores [...] Há ainda questões que não se referem diretamente às expectativas de aprendizagem, quer para o ano em questão, quer para os seguintes, mas que foram propostas porque, de alguma forma, contribuem com os processos de compreensão ou produção dos textos, objetivo maior de qualquer material didático ou prática pedagógica (SÃO PAULO, 2010, p. 11).
}

INFLUÊNCIAS NA CONSTITUIÇÃO DO CURRÍCULO OFICIAL NA RME-SP: POSSIBILIDADES DE INTERPRETAÇÃO

A análise da documentação curricular oficial da RME-SP evidenciou um contexto de múltiplas determinações na constituição do currículo. Uma das mais destacadas nesse processo é a avaliação externa, que pôde ser apreendida nas três frentes curriculares. No Referencial de Língua Portuguesa, tais avaliações aparecem como um importante parâmetro quanto ao nível de alfabetização dos estudantes brasileiros: 
Ao observar dados de que dispomos de instituições que avaliam a capacidade leitora dos alunos, é possivel constatar que ler é uma atividade difícil para quem frequenta as escolas do Brasil. As avaliações do Sistema de Avaliação da Educação Básica (Saeb), do Programa Internacional de Avaliação do Aluno (Pisa), do Sistema de Avaliação do Rendimento Escolar do Estado de São Paulo (Saresp) e da Avaliação Nacional do Rendimento Escolar

(Anresc) mostram que poucos são capazes de compreender textos longos, identificar e recuperar informações literais, formular hipóteses interpretativas, sintetizar e avaliar criticamente o que leem. A maioria do alunado brasileiro tem habilidades leitoras pouco desenvolvidas e, consequentemente, não usufruem as inúmeras possibilidades de formação que os textos podem oferecer. Por isso, o grande desafio de toda escola e, principalmente, de nós, professores de Língua Portuguesa, é desenvolver habilidades leitoras que preparem os alunos para lidar com as diversas situações que a cultura letrada apresenta (SÃO

Ainda sobre o Programa Ler e Escrever há uma série de apresentações disponíveis no site da SME que foram produzidas por ocasião de seu

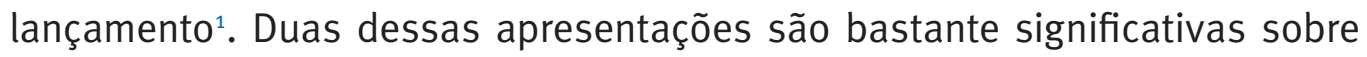
o tipo de orientações que pautaram a implementação do Programa na Rede. A primeira delas elenca um perfil da população brasileira de acordo com 0 Indicador de Analfabetismo Funcional (Inaf) de 2005, relacionando o fato de apenas $26 \%$ da população ter domínio pleno da alfabetização com a necessidade de se pensarem estratégias da escola para assegurar um bom desempenho na leitura e escrita, considerando, por meio de dados que são apresentados, que o aumento dos anos de estudos não garante o incremento no domínio da língua. Com base nessas constatações, o texto apresenta uma série de ações que devem ser organizadas pelo professor alfabetizador para assegurar que os alunos do 1ํano acessem a língua de maneira plena.

A segunda apresentação disponível no site utiliza dados da Prova Brasil para apresentar a necessidade de determinadas habilidades em leitura e escrita serem trabalhadas pela escola. O Referencial para o ciclo II é apresentado ao final de uma longa explicação sobre os níveis de cada escala e a apresentação dos resultados do município ante o país, dando amplo destaque para o fato de que o desempenho global do município está abaixo das médias estadual e federal.

As Orientações Curriculares, por sua vez, apresentam uma ligação mais tênue com as avaliações. É importante destacar que elas foram elaboradas em um processo simultâneo à criação de um sistema próprio de avaliação externa na

Essas apresentações não apresentam uma data específica de publicação e podem ser encontradas no site da SME-SP. Disponível em: 〈http://www.portalsme.prefeitura. sp.gov.br/Projetos/fundemedio/Anonimo/lereescreverencontros.aspx>. Acesso em: 24 fev. 2014. 
RME-SP, sendo pouco evidente a influência direta da Matriz de Referência da Avaliação (SÃO PAULO, 2007g) com esse documento.

A ligação dos Cadernos com as avaliações externas é bastante explícita, uma vez que foram elaborados com base nas dificuldades apresentadas pelos alunos na Prova São Paulo e na Prova da Cidade, conforme relato no site da Secretaria ${ }^{2}$. Esse é um indício bastante forte da influência da avaliação externa no currículo, visto que é possível supor - embora não generalizar - que os Cadernos sejam utilizados em larga medida pelos professores da Rede, complementando ou não outros materiais.

Assim, tanto nos Cadernos quanto na Prova São Paulo, as atividades propostas partem de textos - representativos dos gêneros textuais estudados no respectivo ano - para que sejam verificadas as habilidades dos alunos. É interessante observar que esse material didático se compõe, basicamente, de exercícios. Sua função, portanto, é muito mais trabalhar o desenvolvimento das habilidades na resolução desses exercícios do que reforçar os conceitos das esferas de circulação e gêneros.

É possível identificar, na construção dos exercícios dos Cadernos, que eles dialogam tanto com as Orientações Curriculares quanto com as Matrizes de Referência da Prova São Paulo. Cada um dos exercícios se refere às expectativas de aprendizagem presentes nas Orientações Curriculares. Tais expectativas, contudo, são traduções de habilidades, considerando a definição do termo a partir do que está nas Matrizes de Referência, a qual seja: “[...] funcionam como indicadores ou descritores do que o aluno deve demonstrar como desempenho e permitem concluir se houve de fato aprendizagem e em que nível ela ocorreu" (SÃO PAULO, 2007g, p. 12). Ademais, a análise dos exercícios propostos evidencia que há - em nível crescente de complexidade - um trabalho que busca estimular o desenvolvimento dos grupos de competências mensuradas na avaliação externa: recuperação de informações nos textos, compreensão e interpretação de textos e reflexão de conteúdos e formas de textos.

Essas informações, assim, se não permitem afirmar que o currículo está sendo pautado pelas avaliações, ao menos indicam que houve uma forte influência dos resultados de avaliações externas na elaboração desses programas enquanto política de currículo da Rede, cujo objetivo seria sanar a constatada fragilidade no que diz respeito ao domínio da Língua Portuguesa.

Disponível em: 〈http://www.portalsme.prefeitura.sp.gov.br/Projetos/BibliPed/Anonimo/ Cadernosdeapoio.aspx?MenulD=38\&MenulDAberto=12〉. Acesso em: 28 jul. 2013. 
Outro interessante fator de influência observado, que merece destaque, foi apreendido no material do Ler e Escrever para o 3 ano. São propostos, nesse ano, sequências de trabalho anuais envolvendo a utilização da revista Recreio, da Editora Abril, que mantinha um contrato com a RME-SP. No entanto, não havia nenhuma justificativa para a utilização específica dessa revista, o que permite o questionamento acerca de essa escolha estar relacionada com uma questão contratual.

Por fim, e não menos importante, é necessário considerar ainda que há uma relevante influência político-partidária na composição dos currículos oficiais. Se observado o histórico da RME-SP, desde 1989 toda mudança de gestão envolveu uma reorganização curricular intensiva (AGUIAR, 2011), tendência que parece estar mais ligada à necessidade de se deixar uma "marca de governo" do que a uma verdadeira preocupação com a qualidade do ensino ofertado pelas escolas da Rede. Desse modo, o caso da RME-SP evidencia que o contexto de produção curricular oficial possui múltiplos determinantes, que vão desde a existência de um cenário de avaliações externas até questões políticas. 


\section{Influences in the constitution of São Paulo's municipal education network official curriculum}

Abstract: Curricular policies occupy a central place on the education debate. As a result of adopting these policies as propellers for change by federal, state, and municipal administration, such theme has been gaining momentum in Brazilian scholarly production. Educational changes and other aspects involved in such processes on the last decades have also generated a specific effect on curriculum. By investigating elementary education's curricular policy in São Paulo's municipal education network the present article weighs up which would be the possible influences on its constitution. Such investigation focuses on policies formulation between years 2005 and 2012, trying to evidence influences such as external evaluations, political-partisan and commercial issues.

Keywords: Official curriculum. External evaluation and curriculum. São Paulo’s municipal education network. 


\section{REFERÊNCIAS}

AGUIAR, Denise Regina da C. A proposta de política pública educacional no município de São Paulo: a (des) construção de uma escola pública popular, democrática e com qualidade. $25^{\circ}$ Simpósio Brasileiro de Política e Administração da Educação. Apresentação de Comunicação Oral. 2011. Disponível em: 〈http://www.anpae.org.br/simposio2011/cdrom2011/PDFs/ trabalhosCompletos/comunicacoesRelatos/0132.pdf>. Acesso em: 18 abr. 2013.

BARRETTO, Elba S. de S. Tendências recentes do ensino fundamental no Brasil. In: - (Coord.) Os currículos do ensino fundamental para as escolas brasileiras. Campinas: Autores Associados, 1998, p. 5-42. - Tendências recentes do currículo na escola básica. Difusão de ideias, São Paulo: Fundação Carlos Chagas, dez. 2006.

DUSSEL, Inês. O currículo híbrido: domesticação ou pluralização das diferenças? In: LOPES, Alice. C.; MACEDO, Elizabeth. (Orgs.). Currículo: debates contemporâneos. São Paulo: Cortez, 2010 (Série Cultura, Memória e Currículo, v. 2), p. 55-77.

FIGUEIREDO, Marcus. F.; FIGUEIREDO, Argelina M. C. Avaliação política e avaliação de políticas: um quadro de referência teórica. Análise \& Conjuntura. Belo Horizonte, v. 1, n. 3, p. 107-27, set./dez. 1986.

LOPES, Alice C. Políticas curriculares: continuidade ou mudança de rumos? Revista Brasileira de Educação, Rio de Janeiro, n. 26, p. 109-118, ago. 2004. ; MACEDO, Elizabeth. O pensamento curricular no Brasil. In: . (Orgs.) Currículo: debates contemporâneos. São Paulo: Cortez, 2010. (Série Cultura, Memória e Currículo, v. 2), p. 13-54.

MOREIRA, Antonio Flávio B. Currículos e programas no Brasil. Campinas: Papirus, 2012.

SACRISTÁN, J. Gimeno. O que significa currículo? In: (Org.). Saberes e incertezas sobre o currículo. Porto Alegre: Penso, 2013, p. 17-35.

SÃO PAULO (Município). Secretaria Municipal de Educação. Portaria no 6.328 de 26 de setembro de 2005. Institui, para o ano de 2006, o Programa "Ler e escrever - prioridade na Escola Municipal”, nas Escolas Municipais de Ensino 
Fundamental - EMEFs e Escolas Municipais de Ensino Fundamental e Médio EMEFMs. Diário Oficial da Cidade de São Paulo, São Paulo, 27 set. 2005a, p. 20.

Projeto toda força ao $1^{0}$ ano: guia para o planejamento do professor alfabetizador - orientações para o planejamento e avaliação do trabalho com o $1^{\text {ํ }}$ ano do ensino fundamental - v. 1. São Paulo: SME/DOT, 2006a.

Projeto toda força ao 1을 ano: guia para o planejamento do professor alfabetizador - orientações para o planejamento e avaliação do trabalho com o $1^{\circ}$ ano do ensino fundamental - v. 2. São Paulo: SME/DOT, 2006b.

Projeto toda força ao $1^{0}$ ano: guia para o planejamento do professor alfabetizador - orientações para o planejamento e avaliação do trabalho com o $1^{\circ}$ ano do ensino fundamental - v. 3. São Paulo: SME/DOT, 2006c.

. Referencial de expectativas para o desenvolvimento da competência leitora e escritora no ciclo II do ensino fundamental. São Paulo: SME/DOT, 2006d.

- Referencial de expectativas para o desenvolvimento da competência leitora e escritora no ciclo II: caderno de orientação didática de Língua Portuguesa. São Paulo: SME/DOT, 2006e.

. Portaria n- 5.403, de 16 de novembro de 2007. Reorganiza o Programa “Ler e Escrever - Prioridade na Escola Municipal” nas Escolas Municipais de Ensino Fundamental - EMEFs, Escolas Municipais de Ensino Fundamental e Médio - EMEFMs e Escolas Municipais de Educação Especial - EMEEs. Diário Oficial da Cidade de São Paulo, São Paulo, 17 nov. 2007a.

Guia de planejamento e orientações didáticas para o professor do $2^{0}$ ano - v. 1. São Paulo: SME/DOT, 2007b.

. Guia de planejamento e orientações didáticas para o professor do $2^{0}$ ano - v. 2. São Paulo: SME/DOT, 2007c.

- Portaria no 4.507, de 30 de agosto de 2007. Institui, na rede municipal de ensino, o programa "Orientações Curriculares: Expectativas de Aprendizagens e Orientações Didáticas” para a educação infantil e ensino fundamental e dá outras providências. Diário Oficial da Cidade de São Paulo, São Paulo, 31 ago. 2007d, p. 12.

- Orientações curriculares e proposição de expectativas de 
aprendizagem para o ensino fundamental: ciclo I. São Paulo: SME/DOT, 2007e.

- Orientações curriculares e proposição de expectativas de aprendizagem para o ensino fundamental: ciclo II - língua portuguesa. São Paulo: SME/DOT, 2007f.

. Matrizes de referência para a avaliação do rendimento escolar. São Paulo: SME, 2007g.

. Guia de planejamento e orientações didáticas para o professor do $3^{0}$ ano. São Paulo: SME/DOT, 2008a.

Guia de planejamento e orientações didáticas para o professor de $4^{\circ}$ ano. São Paulo: SME/DOT, 2008b.

. Cadernos de apoio e aprendizagem: língua portuguesa/Programa Ler e Escrever e Orientações Curriculares. (Quinto Ano) São Paulo: Fundação Padre Anchieta, 2010.

. Projeto intensivo no ciclo I - 3ํano - Livro do Professor. São Paulo: SME/DOT, 2011a.

. Projeto intensivo no ciclo I - 40 ano - língua portuguesa. Livro do Professor. São Paulo: SME/DOT, $2011 b$.

SILVA, Tomaz. T. Documentos de identidade: uma introdução às teorias do currículo. Belo Horizonte: Autêntica, 2011.

SOUZA, Rosa Fátima de. A produção intelectual brasileira sobre currículo a partir dos anos 80. Em Aberto, Brasília, ano 12, n. 58, p. 117-128, abr./jun. 1993.

RECEBIDO: Fevereiro de 2014.

APROVADO: Abril de 2014. 